\title{
Relationship of p73 gene polymorphism and additional gene- smoking and gene-obesity interaction with non-small cell lung cancer risk
}

\author{
Qiuge Wu ${ }^{1}$, Yan Shi ${ }^{1}$, Lulu Ge ${ }^{1}$, Dongbo Ma ${ }^{1}$, Hui Zhang ${ }^{1}$, Jing Wang ${ }^{1}$ \\ ${ }^{1}$ Department of Respiratory and Critical Care Medicine, The First Affiliated Hospital of Zhengzhou University, Henan, China \\ Correspondence to: Jing Wang, email: wangjingdd8868@163.com \\ Keywords: non-small cell lung cancer, G4C14-to-A4T14, polymorphism, interaction, smoking \\ Received: October 09, 2016 Accepted: March 01, 2017 Published: March 16, 2017 \\ Copyright: Wu et al. This is an open-access article distributed under the terms of the Creative Commons Attribution License (CC-BY), which \\ permits unrestricted use, distribution, and reproduction in any medium, provided the original author and source are credited.
}

\section{ABSTRACT}

Aim: The aim of this study was to investigate the impact of G4C14-to-A4T14 polymorphism within P73 gene and additional interactions with current smoking and obesity on non-small cell lung cancer (NSCLC) risk in a Chinese population.

Results: Logistic regression analysis showed a significant association between genotypes of the AT allele in G4C14-to-A4T14 and decreased NSCLC risk. NSCLC risk was significantly lower in carriers of the G4C14-to-A4T14- AT allele than those with GC/GC genotype (AT/AT + GC/AT versus GC/GC), adjusted OR $(95 \% \mathrm{CI})=0.68(0.55-0.93)$. We also found that the OR $(95 \% \mathrm{CI})$ was $1.88(1.32-2.47)$ for current smokers compared with never smokers and $0.69(0.40-0.95)$ for obese subjects compared to participants with normal BMI. Never smokers with AT/AT or GC/AT of the G4C14-toA4T14 genotype have the lowest NSCLC risk compared with smokers with the GC/ GC genotype after covariates adjustment, OR $(95 \% \mathrm{CI})=0.52(0.26-0.87)$. Obese participants with G4C14-to-A4T14- AT/AT or GC/AT genotype have the lowest NSCLC risk compared with non- obese subjects with the GC/GC genotype after adjusting for covariates, OR $(95 \% \mathrm{CI})=0.56(0.33-0.85)$.

Materials and Methods: A logistic regression model was used to examine the association between G4C14-to-A4T14 polymorphism and NSCLC, and its interaction with current smoking and obesity. The odds ratios (OR) and $95 \%$ confident intervals (95\%CI) were calculated.

Conclusions: Our results support an important association between the G4C14to-A4T14 and decreased NSCLC risk and additional impact of an interaction between G4C14-to-A4T14 and smoking or obesity on NSCLC risk.

\section{INTRODUCTION}

Non-small cell lung cancer (NSCLC) was a subtype for lung cancer (LC), and was the main cause of cancerrelated deaths around the world [1,2]. The NSCLC incidence was largely determined by tobacco smoking. Recent years, LC rates have been increasing rapidly in China, where the smoking rates were also increased rapidly [2]. However, not all lung cancer cases have the smoking history $[3,4]$. Therefore, genetic factors were considered as other important risk factors for lung cancer, and LC susceptibility could be influenced by both environmental and genetic factors, and their gene-environment interactions. Recently, epidemiologic studies [5-7] also indicated that overall obesity, as measured by body mass index (BMI) was associated with a reduced susceptibility to lung cancer.

The p73 gene was located at human chromosome $1 \mathrm{p} 36.33[8,9]$. It has been suggested that commonly loss of heterozygosity ( $\mathrm{LOH})$ existed in many subtypes of cancer $[8,10,11]$, and $\mathrm{LOH}$ rate at the p73 gene was high $(62 \%)$ among lung cancer patients [12]. Recently, a kind of polymorphism involves two single-nucleotide polymorphisms (SNPs) at positions $4(\mathrm{G}-\mathrm{A})$ and $14(\mathrm{C}-\mathrm{T})$ (G4C14-to-A4T14) were more reported [8]. Several previous studies have indicated the association between G4C14-to-A4T14 and NSCLC risk in different populations [13-15]; however, they concluded inconsistent results. In 
addition, more and more evidence suggested that lung cancer was significantly associated with both genetic factor and environmental factors in the general population. Smoking have an important role in NSCLC, and two studies $[16,17]$ have focused on the interaction between P73 gene and some environmental factors on lung cancer risk, but they obtained conflicting results. No study focused on the interaction between P73 gene and obesity, which was also an important risk factor for lung cancer [5-7]. Thus, the aim of this study was to investigate the impact of G4C14-to-A4T14 polymorphism and additional interactions with current smoking and obesity on NSCLC risk in a Chinese population.

\section{RESULTS}

A total of 1382 participants with a mean age of $68.1 \pm 13.9$ years were selected, including 764 males and 618 females, consist of 460 NSCLC cases and 922 controls. Table 1 shows the general characteristics for cases and controls. The distributions for obesity, both smoking and drinking, current smokers were significantly differed between the cases and controls. The mean of BMI was lower in the NSCLC cases than the controls.

No significant difference in genotype frequencies from the Hardy-Weinberg equilibrium test was noted for any tested SNPs in the controls $(P=0.691)$. The frequency for the GC/ GC allele of G4C14-to-A4T14 was lower in the NSCLC cases than that in controls. The genotypes with the AT allele in G4C14-to-A4T14 were associated with decreased NSCLC risk after adjusting for age, gender, current smoking, drinking and BMI. NSCLC risk was significantly lower in carriers of G4C14-to-A4T14- AT allele than those with GC/GC genotype (AT/AT + GC/AT versus $\mathrm{GC} / \mathrm{GC})$, adjusted $\mathrm{OR}(95 \% \mathrm{CI})=0.68(0.55-0.93)$ (Table 2). We also found that the OR (95\%CI) was 1.88 (1.32-2.47) for current smokers compared with never smokers and $0.69(0.40-0.95)$ for obese subjects compared to participants with normal BMI (Table 3).

Stratified logistic regression analysis was used to detect the interaction between G4C14-to-A4T14 with smoking and obesity. We found that never smokers with AT/ AT or GC/ AT of the G4C14-to-A4T14 genotype have the lowest NSCLC risk compared with smokers with the GC/ GC genotype after covariate adjustment, OR $(95 \% \mathrm{CI})=0.52(0.26-0.87)($ Table 4$)$. We also found that obese participants with G4C14-to-A4T14- AT/AT or GC/AT genotype have the lowest NSCLC risk compared with non- obese subjects with the GC/GC genotype after adjusting for covariates, $\mathrm{OR}(95 \% \mathrm{CI})=0.56(0.33-0.85)$ (Table 5).

\section{DISCUSSION}

In this study, genotypes of the AT allele in G4C14to-A4T14 was associated with decreased NSCLC risk in this Chinese population. NSCLC susceptibility was lower in carriers with the AT allele of the G4C14-to-A4T14 polymorphism than those with $\mathrm{GC} / \mathrm{GC}$ genotype after adjustment. Although P73 mutation was rare in several diseases, $\mathrm{LOH}$ at P73 locus was relatively common in lung cancer [18]. As we all known that two common SNPs have been identified to be in complete linkage disequilibrium with each other as one variation [8]. Studies have reported a direct effect of G4C14-to-A4T14 on cancer progression, particular for NSCLC risk [19, 20]. Although P73 G4C14-to-A4T14 polymorphism and its relationship with many types of cancer susceptibility have been reported previously [21, 22], few studies focused on impact of this polymorphism on NSCLC risk and the results obtained from previous studies were inconsistent. Choi et al. [23] suggested no association between the p73 G4C14-to-A4T14 polymorphism and LC risk in a Korean population. $\mathrm{Hu}$ et al. [24] reported that polymorphism of p73 gene was associated with a reduced LC risk in a Chinese population. However, Li et al. [16] suggested that the persons with GC/AT and AT/AT genotypes have higher LC risk. Up to now, we found limited human population study investigating the relationship between G4C14to-A4T14 polymorphism and NSCLC risk. Wang et al. [13] indicated that the distribution for G4C14-to-A4T14 genotype was significantly different between NSCLC cases and controls. The sample in this study was relative small, so the results obtained from this study should be checked in other studies with larger sample. Wang et al. [14] also conducted another study and found that the p73 G4C14-A4T14 polymorphism and susceptibility was correlated with LC risk, but the sample size of this study was relatively small, so this association also needs further research. Another study [25] suggested that p73 may play an important role in regulating the cellular response of NSCLC to chemotherapy. Another study by Liu et al. [26] suggested that P73 G4C14-to-A4T14 polymorphisms may serve as promising biomarkers for individualized chemotherapy and prognosis of NSCLC patients.

Tobacco smoking has been widely reported important environmental risk factors for NSCLC. A recent study [27] reported that $88 \%$ of the cases of non-smokers with lung cancer were females. The NSCLC incidence was largely determined by tobacco smoking. Recent years, LC rates have been increasing rapidly in China, where the smoking rates were also increased rapidly [2]. Obesity was another modifiable risk factor for some types of cancer, including colon cancer, postmenopausal breast cancer, and so on [28]. This relationship was still inconclusive for lung cancer. In this study, we found that the smoking rate was higher in cases than that in controls; in contrast, the obesity rate was higher in controls than that in cases. In this study, we also investigated the impact of gene- smoking and gene- obesity interaction on NSCLC risk, and we found that NSCLC risk was the lowest in never smokers with AT/AT or GC/AT of the G4C14-to- 
Table 1: General characteristic of study participants in cases and controls

\begin{tabular}{lccc}
\hline \multicolumn{1}{c}{ Variables } & $\begin{array}{c}\text { NSCLC Cases } \\
(\boldsymbol{n}=\mathbf{4 6 0})\end{array}$ & $\begin{array}{c}\text { Controls } \\
(\boldsymbol{n}=\mathbf{9 2 2})\end{array}$ & $\boldsymbol{p}$-values \\
\hline Age (year) & $68.7 \pm 15.8$ & $67.2 \pm 14.6$ & 0.080 \\
Males $N(\%)$ & $246(53.5)$ & $518(56.2)$ & 0.371 \\
Alcohol consumption $N(\%)$ & $166(36.1)$ & $326(35.4)$ & 0.836 \\
Current smokers $N(\%)$ & $183(39.8)$ & $214(23.2)$ & $<0.001$ \\
Both smoking and drinking $N(\%)$ & $138(30.0)$ & $161(17.5)$ & $<0.001$ \\
BMI $\left(\mathrm{kg} / \mathrm{m}^{2}\right)$ & $23.4 \pm 8.9$ & $24.7 \pm 8.6$ & 0.009 \\
Obesity $N(\%)$ & $123(26.7)$ & $338(36.6)$ & $<0.001$ \\
WC $(\mathrm{cm})$ & $81.6 \pm 14.3$ & $82.4 \pm 14.8$ & 0.338 \\
\hline
\end{tabular}

Note: Means \pm standard deviation for age, WC and BMI. Abbreviations: WC, waist circumference; BMI, body mass index.

Table 2: Genotype and allele frequencies for p73 G4C14-to-A4T14 polymorphism in cases and controls

\begin{tabular}{|c|c|c|c|c|c|}
\hline \multirow{2}{*}{$\begin{array}{l}\text { Genotypes and } \\
\text { Alleles }\end{array}$} & \multicolumn{2}{|c|}{ Frequencies N (\%) } & \multirow{2}{*}{$O R(95 \% C I)^{a}$} & \multirow{2}{*}{$\begin{array}{l}P \text {-values for genotype } \\
\text { and allele frequencies }\end{array}$} & \multirow{2}{*}{$H W E$ test } \\
\hline & $\begin{array}{c}\text { NSCLC Cases } \\
\quad(n=460)\end{array}$ & $\begin{array}{l}\text { Controls } \\
(n=922)\end{array}$ & & & \\
\hline \multicolumn{6}{|l|}{ Additive } \\
\hline $\mathrm{GC} / \mathrm{GC}$ & $294(63.9)$ & $490(53.1)$ & 1.00 & \multirow{3}{*}{$<0.001$} & 0.691 \\
\hline GC/AT & $149(32.4)$ & $361(39.2)$ & $0.71(0.58-0.92)$ & & \\
\hline AT/AT & $17(3.7)$ & $71(7.7)$ & $0.62(0.42-0.96)$ & & \\
\hline \multicolumn{6}{|l|}{ Dominant } \\
\hline $\mathrm{GC} / \mathrm{GC}$ & $294(63.9)$ & $490(53.1)$ & 1.00 & \multirow[b]{2}{*}{$<0.001$} & \\
\hline $\mathrm{AT} / \mathrm{AT}+\mathrm{GC} / \mathrm{AT}$ & $166(36.1)$ & $432(46.8)$ & $0.68(0.55-0.93)$ & & \\
\hline \multicolumn{6}{|l|}{ Recessive } \\
\hline $\mathrm{GC} / \mathrm{GC}+\mathrm{GC} / \mathrm{AT}$ & $443(96.3)$ & $851(92.3)$ & 1.00 & \multirow[b]{2}{*}{0.004} & \\
\hline AT/AT & $17(3.7)$ & $71(7.7)$ & $0.62(0.38-1.03)$ & & \\
\hline \multicolumn{6}{|l|}{ Allele } \\
\hline $\mathrm{GC}$ & $737(80.1)$ & $1341(72.7)$ & & \multirow{2}{*}{$<0.001$} & \\
\hline AT & $183(19.9)$ & $503(27.3)$ & & & \\
\hline
\end{tabular}

${ }^{a}$ Adjusted for gender, age, current smoking, drinking and BMI.

A4T14 genotype, and the highest in smokers with the GC/GC genotype. In addition, NSCLC risk was also the lowest in obese participants with AT/AT or GC/AT of the G4C14-to-A4T14 genotype, and the highest in non- obese subjects with the GC/GC genotype. Two previous studies have focused on the impact of interaction between P73 gene and environmental risk factors on NSCLC risk, such as gender and age [16] and smoking [17]. Li et al. [16] suggested that the lung cancer risk associated with the AT allele (GC/AT+AT/AT) were more pronounced in younger $(</=50$ years $)$ individuals, men, and light smokers. Hiraki et al. [17] have observed the P73 gene- heavy smoking interaction on LC risk, but they concluded negative results. But in this study, we verified a significant interaction of
G4C14-to-A4T14 gene- smoking and obesity interaction on NSCLC risk.

The limitations of this study should be considered. Firstly, the smoking and drinking rates in females were very low, so we could not performed sex difference analysis on this association. Secondly, the gene-gene interaction with other SNPs of P73 or other genes should be investigated in future studies. Thirdly, more environmental factors should be included in geneenvironment interaction studies. Lastly, it could not omit the fact that weight loss maybe an expected side effect in lung cancer, we could not verify the time sequence for obesity and NSCLC occurrence, so this interaction effect should be verified by cohort study in the future. 
Table 3: the association between smoking and obesity and NSCLC risk

\begin{tabular}{|c|c|c|c|c|}
\hline \multirow{2}{*}{$\begin{array}{c}\text { Genotypes and } \\
\text { Alleles }\end{array}$} & \multicolumn{2}{|c|}{ Frequencies $N(\%)$} & \multirow{2}{*}{ OR $(95 \% C I)$} & \multirow{2}{*}{$P$-values } \\
\hline & Cases $(n=460)$ & Controls $(n=922)$ & & \\
\hline \multicolumn{5}{|l|}{ Smoking } \\
\hline Never & $277(60.2)$ & $708(76.8)$ & 1.00 & $<0.001^{\mathrm{a}}$ \\
\hline Currently & $183(39.8)$ & $214(23.2)$ & $1.88(1.32-2.47)$ & \\
\hline \multicolumn{5}{|l|}{ Obesity } \\
\hline No & 337 (73.3) & $584(63.3)$ & 1.00 & $0.020^{\mathrm{b}}$ \\
\hline Yes & $123(26.7)$ & 338 (36.6) & $0.69(0.40-0.95)$ & \\
\hline
\end{tabular}

${ }^{\mathrm{a}}$ Adjusted for gender, age, drinking and BMI.

${ }^{\mathrm{b}}$ Adjusted for gender, age, drinking and smoking.

Table 4: Interaction between p73 G4C14-to-A4T14 and smoking on ESCC risk

\begin{tabular}{lccc}
\hline G4C14-to-A4T14 & Smoking & OR $(\mathbf{9 5 \%} \text { CI })^{\mathbf{a}}$ & $\boldsymbol{P}_{\text {-values }}$ \\
\hline GC/GC & Currently & 1.00 & - \\
GC/GC & Never & $0.69(0.48-0.94)$ & 0.032 \\
AT/AT + GC/AT & Currently & $0.75(0.57-1.03)$ & 0.081 \\
AT/AT + GC/AT & Never & $0.52(0.26-0.87)$ & $<0.001$ \\
\hline
\end{tabular}

${ }^{a}$ Adjusted for gender, age, drinking and BMI.

Table 5: Interaction between p73 G4C14-to-A4T14 and obesity on ESCC risk

\begin{tabular}{lccc}
\hline \multicolumn{1}{c}{ G4C14-to-A4T14 } & Obesity & OR $(\mathbf{9 5 \%} \mathbf{C I})^{\mathbf{a}}$ & $\boldsymbol{P}$-values \\
\hline $\mathrm{GC} / \mathrm{GC}$ & No & 1.00 & - \\
$\mathrm{GC} / \mathrm{GC}$ & Yes & $0.64(0.42-0.92)$ & 0.020 \\
$\mathrm{AT} / \mathrm{AT}+\mathrm{GC} / \mathrm{AT}$ & No & $0.72(0.48-0.95)$ & 0.012 \\
$\mathrm{AT} / \mathrm{AT}+\mathrm{GC} / \mathrm{AT}$ & Yes & $0.56(0.33-0.85)$ & $<0.001$ \\
\hline
\end{tabular}

${ }^{a}$ Adjusted for gender, age, drinking and smoking.

In conclusion, we found that P73 G4C14-to-A4T14 polymorphism was significantly associated with NSCLC risk in Chinese population, genotypes of the AT allele in G4C14-to-A4T14 was associated with decreased NSCLC risk. We also found that never smokers with AT/AT or GC/AT of the G4C14-to-A4T14 genotype have the lowest NSCLC risk compared with smokers with the GC/GC genotype after covariate adjustment. In addition, obese participants with AT/ AT or GC/ AT of the G4C14-toA4T14 genotype have the lowest NSCLC risk compared with non- obese subjects with the GC/GC genotype after adjusting for covariates.

\section{MATERIALS AND METHODS}

\section{Subjects}

This was a case-controlled study on association of G4C14-to-A4T14 polymorphism and gene-environment interaction with NSCLC genetic susceptibility. Chinese patients with NSCLC were consecutively recruited between June 2010 and July 2014 from the First Affiliated Hospital of Zhengzhou University. Patients were diagnosed and sample histology was reviewed in this hospital according to the World Health Organization tumor classification criteria. A total of 460 NSCLC patients were included in the study, controls were matched by sex, age and ethnic background and normal controls with family history of NSCLC were excluded. Blood samples were collected from each participant. Detailed personal information on demographic characteristics, smoking and drinking status were collected via interview. At recruitment, written informed consent was obtained from each participant. We defined current alcohol consumption as more than 1 drink of any type per month or not currently drinking as less than 1 drink of any type per month; current smokers were defined as those who have smoked at least 100 cigarettes and still smoked at the time 
of the interview; individuals with no history of cigarette smoking were considered to be never smokers. Body weight, height, and waist circumference (WC) were also measured according to standardised procedures. BMI was calculated as weight in kilograms divided by the square of the height in metres.

\section{Genomic DNA extraction and genotyping}

Approximately $2 \mathrm{ml}$ of whole blood were collected from all participants in sterile EDTA-coated vacutainers. Genomic DNA from participants was extracted from EDTA-treated whole blood using the DNA Blood Mini Kit (Qiagen, Hilden, Germany) according to the manufacturer's instructions and stored at $-80^{\circ} \mathrm{C}$ until used for genotyping. Genotyping for G4C14-to-A4T14 within P73 gene was performed using the TaqMan platform produced by the BGI Company, China. Genotyping was repeated on a $10 \%$ random sample of study participants, and the results were $100 \%$ concordant. A $25-\mu$ l reaction mixture included 1.25 $\mu \mathrm{l}$ SNP Genotyping Assays $(20 \times)$, $12.5 \mu \mathrm{l}$ Genotyping Master Mix (2×), $20 \mathrm{ng}$ DNA, and conditions as follows: initial denaturation for $10 \mathrm{~min}$ and $95^{\circ} \mathrm{C}$, denaturation for $15 \mathrm{~s}$ and $92^{\circ} \mathrm{C}$, and annealing and extension for $90 \mathrm{~s}$ and $60^{\circ} \mathrm{C}(50$ cycles $)$.

\section{Statistical analysis}

The means and standard deviations (SD) were calculated for normally distributed continuous variables, and the $t$ test was used for comparison between cases and controls; percentages were calculated for categorical variables, and the $\chi^{2}$ test was used for comparison between the case and control group (version 19.0; SPSS Inc., Chicago, IL). HardyWeinberg equilibrium (HWE) was performed using SNPStats (available online at: http://bioinfo.iconcologia.net/SNPstats). A logistic regression model performed by SPSS package (version 19.0; SPSS Inc., Chicago, IL) was used to examine the association between G4C14-to-A4T14 and NSCLC and the interaction between G4C14-to-A4T14 and smoking or obesity. The odds ratios (OR) and 95\% confident intervals $(95 \% \mathrm{CI})$ were calculated. ORs were adjusted for gender, age, smoking and BMI.

\section{ACKNOWLEDGMENTS AND FUNDING}

The writing of this paper was supported by the First Affiliated Hospital of Zhengzhou University. We thank all the partners and staffs who help us in the process of this study. This study was funded by Medical Science and technology project of Henan Province, China. 201602045.

\section{CONFLICTS OF INTEREST}

There is no conflicts of interest.

\section{REFERENCES}

1. Chen W, Zhang S, Zou X. Evaluation on the incidence, mortality and tendency of lung cancer in China. Thorac Cancer. 2010; 1:35-40.

2. Jemal A, Bray F, Center MM, Ferlay J, Ward E, Forman D. Global cancer statistics. CA Cancer J Clin. 2011; 61:69-90.

3. Spitz MR, Wei Q, Dong Q, Amos CI, Wu X. Genetic susceptibility to lung cancer the role of DNA damage and repair. Cancer Epidemiol Biomarkers Prevent. 2003; 12:689-98.

4. Lam WK, White NW, Chan-Yeung MM. Lung cancer epidemiology and risk factors in Asia and Africa. Int $\mathrm{J}$ Tuberc Lung Dis. 2004; 8:1045-57.

5. Kabat GC, Miller AB, Rohan TE. Body mass index and lung cancer risk in women. Epidemiology. 2007; 18:607-612

6. Andreotti G, Hou L, Freeman LEB, Mahajan R, Koutros S, Coble J, Lubin J, Blair A, Hoppin JA, Alavanja M. Body mass index, agricultural pesticide use, and cancer incidence in the Agricultural Health Study cohort. Cancer Causes Control. 2010; 21:1759-1775.

7. Smith L, Brinton LA, Spitz MR, Lam TK, Park Y, Hollenbeck AR, Freedman ND, Gierach GL. Body mass index and risk of lung cancer among never, former, and current smokers. J Natl Cancer Inst. 2012; 104:778-789.

8. Kaghad M, Bonnet H, Yang A, Creancier L, Biscan JC, Valent A, Minty A, Chalon P, Lelias JM, Dumont X, Ferrara P, McKeon F, Caput D. Monoallelically expressed gene related to $\mathrm{p} 53$ at $1 \mathrm{p} 36$, a region frequently deleted in neuroblastoma and other human cancers. Cell. 1997; 90: 809-19.

9. Melino G, Laurenzi VD, Vousden KH. p73: friend or foe in tumorigenesis. Nat Rev Cancer. 2002; 2: 605-15.

10. Bénard J, Douc-Rasy S, Ahomadegbe JC. TP53 family members and human cancers. Hum Mutat. 2003; 21:182-191.

11. Moll UM, Erster S, Zaika A. p53, p63 and p73 - solos, alliances and feuds among family members. Biochim Biophys Acta. 2001; 1552:47-59.

12. Shibukawa K, Miyokawa N, Tokusashi Y, Sasaki T, Osanai S, Ohsaki Y. High incidence of chromosomal abnormalities at lp36 and 9p21 in early-stage central type squamous cell carcinoma and squamous dysplasia of bronchus detected by autofuorescence bronchoscopy. Oncol Rep. 2009; 22: 81-87.

13. Wang SS, Zhu XQ, Yang SD, Dong LL, Li W, Tang J. Association of p73 G4C14-to-A4T14 polymorphism with non-small cell lung cancer risk. Oncol Lett. 2015; 10:995-999.

14. Wang SS, Guo HY, Dong LL, Zhu XQ, Ma L, Li W, Tang JX. Association between a p73 Gene Polymorphism and Genetic Susceptibility to Non-small Cell Lung Cancer in the South of China. Asian Pac J Cancer Prev. 2014; 15:10387-10391. 
15. Zhang X, Li X, Wu Z, Lin F, Zhou H. The p73 G4C14-toA4T14 polymorphism is associated with risk of lung cancer in the Han nationality of North China. Mol Carcinog. 2013; 52:387-91.

16. Li G, Wang LE, Chamberlain RM, Amos CI, Spitz MR, Wei Q. p73 G4C14-to-A4T14 polymorphism and risk of lung cancer. Cancer Res. 2004; 64:6863-6866.

17. Hiraki A, Matsuo K, Hamajima N, Ito H, Hatooka S, Suyama M, Mitsudomi T, Tajima K. Different risk relations with smoking for non-small-cell lung cancer: comparison of TP53 and TP73 genotypes. Asian Pac J Cancer Prev. 2003; 4:107-12.

18. Nomoto S, Haruki N, Kondo M, Konishi H, Takahashi T, Takahashi T, Takahashi T. Search for mutations and examination of allelic expression imbalance of the p73 gene at 1p36.33 in human lung cancers. Cancer. Res 1998; 58:1380-1383.

19. Liu KS, Zhan MY, Zheng PE. Loss of p73 expression in six non-small cell lung cancer cell lines is associated with 5'CpG island methylation. Exp Mol Pathol. 2008; 84:59-63.

20. Uramoto H, Sugio K, Oyama T, Nakata S, Ono K, Nozoe T, Yasumoto K. Expression of the p53 family in lung cancer. Anticancer Res. 2006; 26:1785-90.

21. Li G, Sturgis EM, Wang LE, Chamberlain RM, Amos CI, Spitz MR, El-Naggar AK, Hong WK, Wei Q. Association of a p73 exon 2 G4C14-to-A4T14 polymorphism with risk of squamous cell carcinoma of the head and neck. Carcinogenesis. 2004; 25:1911-1916.

22. Ryan BM, McManus R, Daly JS, Carton E, Keeling PW, Reynolds JV, Kelleher D. A common p73 polymorphism is associated with a reduced incidence of oesophageal carcinamo. Br J Cancer. 2001; 85:1499-1503.

23. Choi JE, Kang HG, Chae MH, Kim EJ, Lee WK, Cha SI, Kim CH, Jung TH, Park JY. No association between p73 G4C14-to-A4T14 polymorphism and the risk of lung cancer in a Korean population. Biochem Genet. 2006; 44:543-50

24. Hu Z, Miao X, Ma H, Tan W, Wang X, Lu D, Wei Q, Lin D, Shen H. Dinucleotide polymorphism of p73 gene is associated with a reduced risk of lung cancer in a Chinese population. Int J Cancer. 2005; 114:455-460.

25. Liu K, Zhuang X, Mai Z. p73 expression is associated with cellular chemosensitivity in human non-small cell lung cancer cell lines. Oncol Lett. 2013; 5:583-587.

26. Liu L, Wu C, Wang Y, Zhong R, Duan S, Wei S, Lin S, Zhang X, Tan W, Yu D, Nie S, Miao X, Lin D. Combined Effect of Genetic Polymorphisms in P53, P73, and MDM2 on Non-small Cell Lung Cancer Survival. J Thorac Oncol. 2011; 6:1793-800.

27. Girard N, Lou E, Azzoli CG, Reddy R, Robson M, Harlan M, Orlow I, Yatabe Y, Nafa K, Ladanyi M, Viale A, Kris MG, Riely G, et al. Analysis of genetic variants in never-smokers with lung cancer facilitated by an Internetbased blood collection protocol: a preliminary report. Clin Cancer Res. 2010;16:755-763.

28. Fair AM, Montgomery K. Energy balance, physical activity, and cancer risk. Methods Mol Biol. 2009; 472:57-88. 